\title{
Externalities from electricity generation and renewable energy. Methodology and application in Europe and Spain*
}

\author{
Anil Markandya \\ Ikerbasque Professor and Director Basque Center for Climate Change (BC3)
}

\begin{abstract}
This paper focuses on the measurements of externalities from electricity generation. These estimates are important for policy design, but they are also controversial because they involve putting money values on environmental burdens and damages such as ill health and reduced life expectancy. We describe the methodology that has been developed to estimate the external costs of electricity generation in the EU and discuss some of the issues involved and how difficulties have been resolved. Following a «life cycle» approach, we provide estimates of external costs for the main fuel sources, including renewables, and we compare them. We also comment on the policy implications.
\end{abstract}

Keywords: Externalities, electricity generation, environmental valuation, life-cycle approach.

JEL classification: $Q 40, Q 42, Q 47$.

\section{Resumen}

Este trabajo analiza la estimación de las externalidades derivadas de la generación de electricidad. Estas estimaciones son importantes para el diseño de políticas, pero cuentan con la dificultad de tener que valorar daños ambientales como los efectos sobre la salud y la esperanza de vida. Se presenta la metodología desarrollada en la UE para estimar las externalidades de la electricidad, incluyendo las principales dificultades y el modo de resolverlas. Mediante un enfoque del «ciclo de vida», se obtienen y comparan las estimaciones de los costes externos asociados a distintas fuentes energéticas, incluyendo las renovables, y se comentan las implicaciones de los resultados para el diseño de políticas.

Palabras clave: externalidades, generación de electricidad, valoración ambiental, enfoque del ciclo de vida.

Clasificación JEL: Q40, Q42, Q47.

\section{Introducción}

It has been well established for some time that generating electricity, especially from fossil fuels, creates impacts on third parties other than the producer of the electricity and the consumer of the electricity. These impacts are referred to as externalities and in the case of electricity generation they are mostly negative, having a damaging impact on the parties concerned. The need for some corrective action to

* Thanks are due to Dr. J. Spadaro who read the paper with care and made a number of suggestions that improved the final version. Any errors and omissions are of course my own. 
address such impacts was recognized a long time ago, by the British economist Pigou, who first noted that if you could tax the activity generating a negative externality, the party responsible would reduce the intensity of that activity. And by selecting the tax level suitably, the authorities could achieve whatever goal they wished in terms of reducing the negative external effects (Pigou, 1932).

The first attempts to control emissions that caused externalities, however, were not based on taxes and did not use any estimates of the damages, either in monetary or physical terms. The measures taken to address this problem involved passing a law, or issuing an administrative order, proscribing certain practices and requiring others to be undertaken. In the UK, for example, factories were ordered, by various parliamentary acts passed between 1820 and 1926, to reduce the output of smoke, and more recently the burning of coal was banned in certain urban areas. As transport became a major source of pollution, the use of more polluting fuels, such as lead, was banned and vehicles were required to be fitted with devices that reduced emissions.

More recently there have been two important developments with respect to externality policy. First we have started to measure the impacts more precisely, including placing monetary values on them, and second we have started to use fiscal instruments to control emissions, through charges per unit emitted, or through mechanisms such as tradable permits. Other fiscal instruments that have been brought into use in recent years include subsidies to cleaner sources with a lower impact on the generation of externalities, as well as indirect fiscal incentives favouring less damaging sources of energy. These include reduced rates of taxation, tax credits and so on.

In this paper I will not discuss the range of instruments available to control externalities but rather focus on the measurements of externalities from electricity generation. The estimates of these damages are important because they guide us on what level of control is appropriate. They are, however, also somewhat controversial because they involve putting money values on environmental burdens and damages such as ill health and reduced life expectancy. Nevertheless estimates of external cost are increasingly used in determining government policies, be it through fiscal measures or through directives that set standards etc. A comparison of costs and benefits of these measures is now undertaken routinely as part of the regulatory impact assessment. Hence it is important to get the best estimates possible.

This paper describes the methodology that has been developed to estimate the external costs of electricity generation in the EU (and other countries in Europe) (Section II). It also discusses some of the issues involved and how difficulties have been resolved. Section III provides estimates of external costs per $\mathrm{kWh}$ for the main fuel sources, including renewables. The latter are not exempt from external costs, partly because of their direct impacts (e.g. wind power creates external costs because people do not like to have landscapes affected by the presence of wind farms but also because it has been argued that they result in loss of bird life). The more important reason for external costs from renewable electricity, however, is that emissions are generated in producing, transporting and disposing of the capital equipment required 
to generate renewable electricity. This «life cycle» approach to estimating external costs is important if we are to get a complete picture of the damages involved and it is the method that has been adopted in the figures given in this paper. The final section of the paper compares the costs from different electricity sources and comments on the policy implications.

\section{Methodology Used in Estimating External Costs}

The approach adopted in this work has been undertaken in Europe (and elsewhere, including North America) and referred to as the Impact Pathway approach (Markandya et al., 2010) ${ }^{1}$. The steps involved are summarised in Figure 1.

This approach starts by identifying a source of emissions, modelling the dispersion of these emissions into the atmosphere and estimating their impacts on health as well as other factors of importance to society. The final stage consists of valuing the impacts.

The modelling of dispersion of emissions is carried out on a $50 \times 50 \mathrm{~km}$ grid that covers all of Europe. Emissions are estimated from all sources, with specified technologies and plant data, such as stack height. The dispersion modelling takes account not only of the local effects from the source but also the long distance dispersion of the pollutants, including through the formation of particles as they are transformed into sulphates and nitrates. Emissions from a source can thus have effects hundreds of kilometres from where they were generated.

The results can be reported in a number of ways but typically an average of damages per $\mathrm{kWh}$ generated is calculated for each country, given the generating plants in that country and their characteristics. Account is taken of the full life cycle of damages, including the extraction of the fuel, its transportation (accidents are important here), the construction of the power generation facility, the combustion or generation of electricity at the plant and the final disposal of the waste. Since some steps are «one-off» (e.g. the construction of the plant), any damages associated with that are attributed to the generation emissions over the lifetime of the plant. This requires the use of a discount rate and estimates that have been made using social real discount rates of 2-3 per cent (see below) ${ }^{2}$.

1 MARKANDYA et al. (2010) provides details of the CASES Project which is a comprehensive review of the state of externality estimation in the electricity sector. Some further work has been undertaken on some specific issues in the NEEDS project, which was completed shortly after the CASES project. See http://www.needs-project.org/ for reports produced under the NEEDs project.

2 i.e. the discount rates are net of inflation. 


\section{FIGURE 1}

\section{THE IMPACT PATHWAY APPROACH}

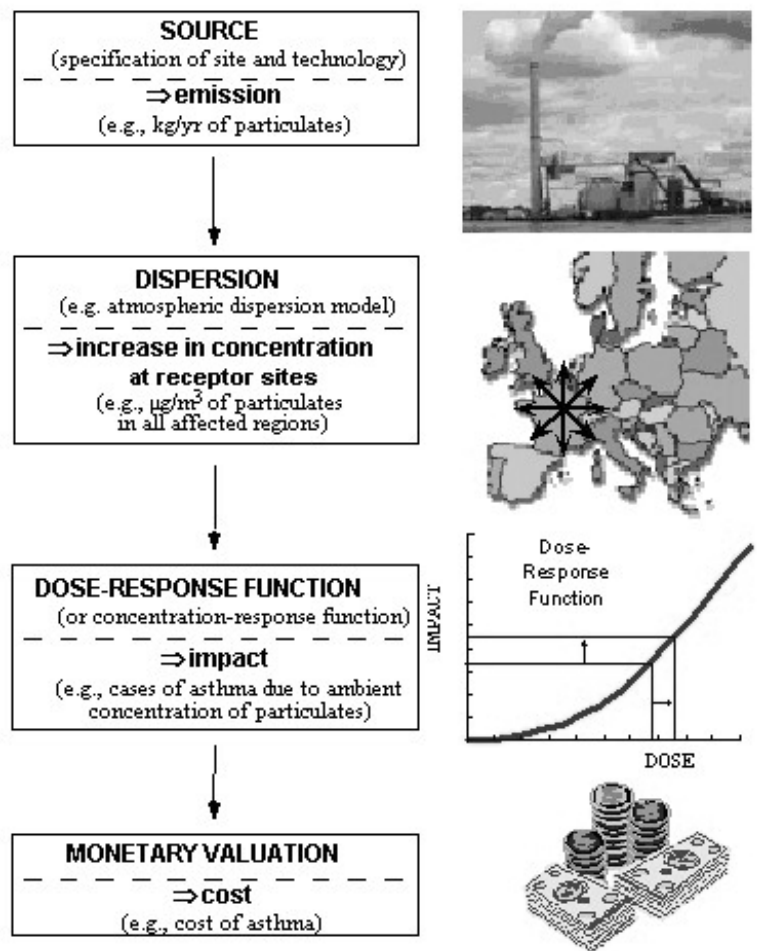

The major issues that arise are those associated with the impacts of the concentrations of pollutants or other factors associated with the operations of the plants. I discuss below some of the key factors that need to be addressed ${ }^{3}$.

\section{Health}

The health impacts are the most important for the fossil fuels. They are based on «dose response functions», which link concentrations of different pollutants (e.g. particles of less than 10 microns in diameter) to certain health «end points» (e.g. loss of life years). The functions are derived from a detailed review of the epidemiological literature. Some of the key functions that have been identified and the health endpoints to which they are linked are given in Table 1. The impact is stated in terms of a health endpoint such as number of years of life expectancy that is lost per microgram per cubic metre a person is exposed to. There is uncertainty

\footnotetext{
${ }^{3}$ Authors sometimes distinguish between external costs and damage costs, using the term for externalities only when action has not been taken to correct for externalities. When such action has been taken optimally any remaining damages are in a true sense not externalities but damage costs.
} 
about this and of course one should look at confidence intervals and not only central values. We discuss that later but here we provide an idea of the kind of impacts that can and have been quantified.

The more controversial issue is the value attached to the endpoints. The aim is to value all such endpoints in terms of the willingness to pay (WTP) to avoid them. So the $\square 40,000$ attached to the loss of a life year is based on the WTP for a year of life and the value of $\square 3$ million for a loss of a child's life is based on WTP measures applied to that. Determining such values is based on a range of methods (see ExternE, 2005), one of which involves asking people how much they would pay for a reduction of such risks. Note that the value for a «life» of 3 million euros is not the value attached to any particular life. It is the value of the reduction of a risk reported as a value of a «statistical life». Thus if a family (or society more widely) is willing to pay $\square 3$ to reduce a child's risk of death by $10^{-6}$ then in a society with a million children the total amount paid would be 3 million euros and this would save one average life $\left(3 / 10^{-6}\right)$, which is referred to as the value of a statistical life ${ }^{4}$.

TABLE 1

\section{KEY IMPACTS ON HEALTH FROM CONCENTRATIONS OF POLLUTANTS GENERATED FROM ELECTRICITY}

\begin{tabular}{|c|c|c|}
\hline Pollutant & Physical Impact & Monetary Value ( $\square$ ) \\
\hline \multicolumn{3}{|c|}{ Primary and Secondary Particles $<2.5$ microns } \\
\hline Life Expectancy Reduction (Years) & $6.51 \times 10^{-4}$ & 40,000 \\
\hline Minor Restricted Activity Days & $3.69 \times 10^{-2}$ & 38 \\
\hline Work Days Lost & $1.39 \times 10^{-2}$ & 295 \\
\hline Other Restricted Activity Days & $9.59 \times 10^{-3}$ & 130 \\
\hline \multicolumn{3}{|c|}{ Primary and Secondary Particles $<10$ microns } \\
\hline Increased Mortality Risk for Infants & $6.84 \times 10^{-8}$ & $3,000,000$ \\
\hline New Cases of Chronic Bronchitis & $1.86 \times 10^{-5}$ & 200,000 \\
\hline Respiratory Hospital Admissions & $7.03 \times 10^{-6}$ & 2,000 \\
\hline Cardiac Hospital Admissions & $4.36 \times 10^{-6}$ & 2,000 \\
\hline Lower Respiratory Symptoms (adult) & $3.24 \times 10^{-2}$ & 38 \\
\hline Lower Respiratory Symptoms (children) & $2.08 \times 10^{-2}$ & 38 \\
\hline
\end{tabular}

SOURCE: MARKANDYA et al. (2010).

Impact is measured per microgram per normal cubic metre of ambient concentration that a population is exposed to. Net refers to all restricted activity days excluding those.

${ }^{4}$ Some researchers prefer to estimate the impacts of concentrations of particles in terms of mortality risk and others in terms of loss of life expectancy. In the former case we use a value of statistical life and in the latter we use the value of a life year lost. The use of life years lost is more common in the health literature where researchers value disability adjusted life years (DALYs). 
In the case of other health endpoints a WTP approach has been taken where possible, but where no studies were available, the actual costs of illness (treatment costs, plus loss of earnings) have been used. Studies show that such costs of illness under estimate the WTP measure by a factor of 2-3 (ExternE, 2005).

\section{Building Materials and Crops}

Concentrations of $\mathrm{SO}_{2}$ and ozone produced through chemical reactions involving primary pollutants from burning fossil fuels cause damage to various building materials, including different kinds of stone, steel, zinc and paint. Rates of corrosion are linked to concentrations through dose response functions.

In the case of crops there is a positive effect on yields of wheat, barley, potato, sugar beet and oats from $\mathrm{SO}_{2}$ from concentrations below 6.8 parts per billion (ppb) but a negative effect thereafter ${ }^{5}$. A similar positive effect is estimated for nitrogen deposition but in this case there is no upper bound. Finally there is a negative impact of accumulated ozone concentration above $40 \mathrm{ppbv}$, which is more significant than that of $\mathrm{SO}_{2}$.

Materials lost and changes in crops yields are valued at market prices.

\section{Impacts and damage to biodiversity}

Impacts to biodiversity occur, among other channels, through acidification and eutrophication of soil from emissions of $\mathrm{SO} 2, \mathrm{NOx}$ and $\mathrm{NH} 3$. The approach used to derive damages involved estimating the potentially disappeared fraction (PDF), i.e. biodiversity losses due to acidification and eutrophication.

In each land type a certain number of species are found and if the soil is polluted for the reasons given above the number and type of species changes and the number of species is reduced. Estimates have been made of this loss of species per unit deposition of the above pollutants and, based on data of deposition per $50 \times 50 \mathrm{~km}$ grid one can estimate the loss of number of species. This loss is then valued based on (a) the costs of restoration of biodiversity loss through soil treatment or (b) the willingness to pay (WTP) for restoration of PDF. The former is estimated at $\square 0.45$ / $\mathrm{PDF} / \mathrm{M} 2$, while the latter is estimated at $\square 0.47 / \mathrm{PDF} / \mathrm{M} 2$ (Ott et al., 2006; Kuik et al., 2008). Since WTP is regarded as a better measure of value the latter has been taken in deriving estimates of biodiversity loss per country and for the EU $27^{6}$.

\footnotetext{
5 This is one of the few «non-linear» relationships found among the dose response functions, which are generally linear at a low dose levels.

6 The above method is designed to be applied at a European scale. It is not therefore valid at the very local level, although it should give reasonable values at the national level.
} 


\section{Greenhouse gases}

Emissions of greenhouse gases are the most difficult to value, given all the uncertainties associated with climate change. Estimates of the damages are based on running an integrated assessment model (IAM) under a baseline set of conditions and then running it with a small change in these conditions such that they result in a marginal reduction in emissions in the present period. The change in the present value of damages divided by the fall in emissions gives the unit value attached to a unit emitted today.

The main factors that account for differences in values are: (a) the discount rate used and (b) the weights attached to damages in poor versus rich countries. The lower the discount rate and the greater the weight attached to losses in poor countries (where the majority of impacts are found to occur), the higher will be the unit value of a ton of $\mathrm{CO}_{2}$ or equivalent greenhouse gas. Furthermore, values will change over time, so emissions in the future will have a higher impact than emissions today. Based on a review of the literature it was concluded that a lower bound was $4 \square / \mathrm{tCO}_{2}$ and an upper bound could be $53 \square / \mathrm{tCO}_{2}$, with a central value of $23 \square / \mathrm{tCO}_{2}$. These are the values for 2000 . For 2030 they go up to $8 \square / \mathrm{tCO}_{2}$ (lower bound), $110 \square / \mathrm{tCO}_{2}$ (upper bound) and $41 \square / \mathrm{tCO}_{2}$ (central value) $)^{7}$.

\section{Non Classical Pollutants and Radionuclides}

The damages from non-classical pollutants (principally heavy metals, As, Cd, $\mathrm{Cr}, \mathrm{Ni}, \mathrm{Pb}, \mathrm{Hg}$ and dioxins) have been calculated based on emissions and inhalation and ingestion pathways estimated in a number of European studies. The figures are European averages and so they are applicable to all European countries. The dose response functions give relationships between inhalation of some of these pollutants and through ingestion of food and water. Morbidity and mortality effects are valued in the same way as indicated above ${ }^{8}$.

In the case of radionuclides only routine radiation has been valued. Emissions of radionuclides measured in bequerels $(\mathrm{Bq})$ give rise to doses measured in man Sieverts (manSv), which are related to increased risks of cancer and hereditary effects. Both mortality and hereditary effects are in terms of a value of statistical life and non-fatal cancers in terms of loss of disability adjusted life years (DALYs). There are a large number of radionuclides that give rise to doses of ManSv through emissions to air and water. Each of these is considered and their effects summed up and applied to the affected population. Since effects of releases today can occur over

\footnotetext{
${ }^{7}$ When we speak of lower and upper bounds we are excluding outliers from the distribution of results that are in the literature.

${ }^{8}$ Additional endpoints that are valued include osteoporosis and renal dysfunction (from Cd), various cancers (from $\mathrm{As}$ ) and anaemia (from $\mathrm{Pb}$ ). One non-health impact is loss of IQ from lead and $\mathrm{Hg}$, which is valued in terms of costs of compensatory education to make good any loss of earnings.
} 
a long period, account has to be taken of that. Future impacts are discounted using rates of 2-3 per cent (see below).

In practice these routine releases are very small and the external effects that result from them are tiny. The main issue with nuclear power generation is accidental releases. These have not been included in the main assessments made, although some secondary assessment of these is available and is commented on in the next section.

\section{Impacts that Have Not been Measured in Monetary Terms}

There are some external costs that have been identified but that could not be valued systematically due to the lack of systematic data at the national or regional level. These include:

- Eutrophication in water bodies. Nutrient inputs such as nitrates and phosphates give rise to pressures on water bodies resulting in blooms, hypoxia and other phenomena that affect fish as well as recreational use of these waters. Although losses due to eutrophication have been estimated the problem is linking physical indicators of nutrient loading to the level of damages. Furthermore additions of nutrients due to power generation are a small part of the loading, which is mainly from agricultural sources. Hence no estimates have been made of the impacts of power generation on this phenomenon.

- Visual Impacts of wind, hydro and transmission lines. These impacts are directly related to the power sector and estimates of some of the effects are available. For example the effects of wind parks have been evaluated for the Nordic countries, France and Spain. Studies also have estimated the visual effects of transmission lines and changes in landscape due to hydropower stations. There are difficulties in valuing damages because they depend on what alternative is presented to the people being questioned (e.g. in the case of transmission lines whether they are buried under ground in the same location or are moved somewhere else). In addition the results show that the values are highly project and site-dependent and not amenable to an up-scaling at the national or regional level. For this reason they have not been included in the reported estimates, although the implications of excluding them are commented on in the next section.

\section{Real Prices and Discounting}

The estimation of external costs from power generation involves valuing emissions at different points in time and (in some cases) valuing the impacts of emissions today on people and the environment in the future. Adjustments have to 
be made therefore for: (a) changes in unit damage values over time, (b) changes in background concentrations against which the additional effects are measured (the levels of these have an effect on marginal damages from precursor emissions and from cases where the dose response function is non-linear). Values of damage are expected to increase with real incomes with an elasticity of WTP with respect to real income of 0.85 (based on time series and cross section studies relating the two variables $)^{9}$. The estimates assume an average annual growth rate for them of 2 per cent to 2030 and 1 per cent thereafter. Background concentrations scenarios are developed of the state of the economy and emissions at future dates. Finally future damages are discounted with a discount rate equal to the growth rate assumed above plus a private rate of time preference of one per cent. Thus the discount rate to 2030 is 3 per cent and 2 per cent thereafter.

\section{Uncertainties}

It is clear that the estimated external costs are uncertain and this uncertainty arises from a multiplicative process in which we go from emissions to concentrations and from concentrations to impacts in physical terms and finally to impacts in value terms. The representation of this process was developed by Rabl and Spadaro (1999), in which the authors note that if the final number (damages/kWh) is the result of a process such as that described above and If the variable at each step has an independent distribution with a given geometric mean, then the square of the geometric standard deviation of the final figure is the sum of the squares of the geometric standard deviations of each process that gives rise to the final product. By the Central Limit Theorem the product of a large number of processes working multiplicatively will tend to the log normal. Hence we can apply the confidence intervals for such a distribution, which states that a 95 per cent confidence interval is given by:

$$
\left[\frac{\mu_{g}}{\sigma_{g}^{2}}, \mu_{g} \sigma_{g}^{2}\right]
$$

Where $\mu_{g}$ is the geometric mean value and $\sigma_{g}$ is the geometric standard deviation. Previous work has found that the value of $\sigma$ for the processes involved in obtaining estimates of damages from the pollutants considered is about 3 for particulates and 5 for $\mathrm{CO}_{2}$ (Spadaro and $\mathrm{Rabl}, 2008$ ). Based on those values we report some uncertainty ranges in the next section.

In the next section we look at the numbers that have been derived on the basis of this methodology for elected European countries and comment on their implications for energy policy.

${ }^{9}$ The elasticity here means the percent increase in WTP for each one percent increase in real income 


\section{Estimates of External Costs}

Table 2 summarises estimates of the private and external costs of electricity generation for selected fuel cycles, both conventional and renewable. The figures are averages for the EU27, as well as for Spain and represent emissions from current technologies across the range of plants currently in operation. If no plants are located in a country and a fictional plant is assumed to be established in a plausible location and the costs arising are estimated on that basis. For conventional sources we have taken the following: heavy oil condensing, hard coal condensing, lignite condensing and natural gas combined cycle ${ }^{10}$. For renewable sources we consider hydropower run of the river (10MW), hydropower with dam and reservoir, wind onshore and offshore, solar PV in an open space and solar trough. It is important to note that the costs given are averages for state of the art plants operating in 2005. There will be variations across plants depending on where they are located. For example a fossil fuel plant very close to a typical city centre could have external costs up to three times higher than one located in a rural area. With a large city the ratio could be high as 6 . There are also differences in costs depending on stack height: a low stack height can result in double the damages compared to a high stack height release.

\section{TABLE 2}

PRIVATE AND EXTERNAL COSTS FOR DIFFERENT FUELS IN EURO CENTS/KWH

\begin{tabular}{|l|c|c|c|c|c|}
\hline & EU27 & \multicolumn{2}{|c|}{ EU27 } & \multicolumn{2}{c|}{ Spain } \\
\hline Fuel & Private & External & Total & External & Total \\
\hline Conventional Fossil Fuel & 6.66 & 2.40 & 8.97 & 1.76 & 8.42 \\
\hline Heavy Oil Condensing & 3.33 & 3.14 & 6.47 & 2.63 & 5.96 \\
\hline Hard Coal Condensing & 2.68 & 2.65 & 5.33 & 2.97 & 5.65 \\
\hline Lignite Condensing & 4.81 & 1.39 & 6.20 & 1.18 & 5.99 \\
\hline Natural Gas Combined Cycle & 3.10 & 0.21 & 3.31 & 0.16 & 3.26 \\
\hline Nuclear & & & & \\
\hline Renewables & 7.83 & 0.06 & 7.89 & 0.04 & 7.87 \\
\hline Hydropower Run of River 10MW & 11.04 & 0.08 & 11.12 & 0.05 & 11.09 \\
\hline Hydropower Dam (with Reservoir) & 6.11 & 0.10 & 6.21 & 0.08 & 6.19 \\
\hline Wind Onshore & 6.36 & 0.09 & 6.45 & 0.07 & 6.43 \\
\hline Wind Offshore & 35.91 & 0.89 & 36.80 & 0.64 & 36.55 \\
\hline Solar PV Open Space & 12.76 & 0.12 & 12.88 & 0.09 & 12.85 \\
\hline Solar Parabolic Trough &
\end{tabular}

SOURCE: CASES Project Output: http://www.feem-project.net/cases/links_databases.php.

${ }_{10}$ We do not consider combined heat and power generation. 
Notwithstanding these qualifications some important conclusions can be drawn from the analysis summarised in the table above. In particular:

- The external costs from fossil fuels are significant and can range from 20 per cent (natural gas CC) to 52 per cent (lignite condensing) of total costs. There can be difference between the EU27 average the external costs in Spain; in general Spain has slightly lower external costs than the EU27 average. One reason could be because the latter is dominated by cost in Central Europe (Germany and Benelux), where population concentrations are greater ${ }^{11}$. Within fossil fuels lignite has the highest costs and natural gas the lowest.

- The sources of external costs for fossil fuels are not shown in the table but they arise mainly from health and clime change. For example, in the case of hard coal 52 per cent are due to climate change effects and about 40 per cent to health effects. These shares vary a little: for natural gas the climate share is smaller and the health share is higher. Nevertheless the two factors together account for most of the external costs. We should also note that the monetary external costs are an underestimate of the total external costs, to the extent that impacts such as visual amenity loss, biodiversity are not included.

- Nuclear is a special case. The private costs are low (not the lowest but among the lowest) and the measured external costs are much lower than all fossil fuels. Yet nuclear is perceived as environmentally dangerous. This is because of the perceived damages from nuclear accidents. Indeed if an accident occurs and there is release of radioactive materials, the damages can be substantial as we witnessed in the recent Fukushima Daiichi plant in Japan. There are two problems with valuing such accidents. First the probability of such an event is difficult to estimate, given the very few events that have occurred. If we base expectations on total loss of life and damages from the three important events that have occurred (Three Mile island in the 1979, Chernobyl in the 1986s and Fukushima in 2011) and divide by the amount of power generated from nuclear plants, the cost per kWh would still be very low. Indeed the number of premature deaths from coal power generation would be orders of magnitude higher than nuclear. Public attitudes to nuclear risk, however, are not determined by such considerations and there is a major element of risk aversion, which is difficult to measure. In some work done more than two decades ago we tried to estimate this risk aversion (Krupnick et al., 1993) and came to the conclusion that standard economic models of decision-making under risk would still result in nuclear power having relatively low external costs (higher than the ones shown in Table 2 of course). Yet is seems that the public debate on nuclear power in many countries is not based on such considerations of externalities and more on public perceptions of fear and dread.

11 Differences in the quality of the fuel can also contribute to differences in the external costs or emissions source characteristics. 
- The external costs of renewable sources are quite low (though not zero), and they are underestimated (as are fossil fuel external costs) to the extent that visual biodiversity impacts are missing. In the case of onshore wind, however, the visual impacts could be important, and biodiversity impacts of both onshore and offshore wind may be important: more work is needed on this, especially offshore wind. Of the different renewables, the highest external costs arise in the case of solar PV, due to the life cycle health effects of obtaining the materials used in the solar units.

- Taking full costs of generation, some renewables would be more competitive with fossil fuels. This is especially the case with wind power; however it is not true for solar power or hydropower with dams. Of course the comparisons may vary from location to location and the averages presented here do not determine the ranking in all cases. Nevertheless they are useful as a guide on where renewable power may be competitive when policy is based on social costs (i.e. the sum of private and external costs). We should also note that over time the private costs of renewables should fall and to some extent the same applies to the private costs of fossil fuels plants. For fossil fuels, we can expect gains in efficiency, so less is emitted per unit generated, but we can expect damages to increase as a higher value is placed on all categories, especially health and climatic effects so the social costs may rise.

- If one takes account of the uncertainties as described in the previous section, the range of external costs becomes very wide. Just to take an example, consider the coal in Spain. Estimates of external costs indicate an average value of 2.63 $\square$ Cents/kWh. Taking a geometric standard deviation of 3, for the PM damages and 5 for CO2 (based on Spadaro and Rabl, 2008) the 95 per cent confidence interval would be from $0.14 \square$ cents to $12.0 \square$ cents/kWh. Knowing this range can inform policy making in a couple of ways. First policy makers may add a «risk premium» to the external cost, so in effect taking a larger value to allow for the possibility that the costs could be much higher. In that case, the incentive to go for renewables would be greater, as the risk premium will be larger for fossil fuels, which have higher mean external costs. Second it justifies more resources to reduce the range through research on the underlying steps in the Impact Pathway. Of course such resources are only justified where a reduction in uncertainty would make a difference to the choice of the source of electricity generation. If, for example, the case for, say, wind over oil in a particular location is valid because the 95 per cent range of total costs for wind and those for oil do not overlap then there is no need for more information. Unfortunately, however, this will not always be the case and some further work on reducing damages is justified. 


\section{Conclusions and Policy Implications}

The literature on externalities has contributed a lot to our understanding of how the production of some goods and services result in costs that are not passed on the final consumers of those goods and services through the normal market channels. In such cases government action can be justified, if reasonable estimates can be made of the damages and if the parties involved cannot arrive at a private solution to 'internalise' these externalities. This is very much the case with electricity generation. The studies undertaken show that generating electricity from fossil fuels results in external costs which add a significant amount to the direct private costs. The external costs are more difficult to determine in the case of nuclear power where the externality approach has not been so successful. In the case of renewable electricity the external costs are much lower (though they are not zero, when account is taken of the life cycle impacts, as is the correct thing to do).

What are the policy implications of these costs? Ideally, a tax should be added to the activity so that the price reflects the full social cost, which is the sum of the private and external cost. Alternatively a tradable permit scheme can achieve the same goal. In both cases resources would be allocated most efficiently. There are problems with such an approach, however. The first is that governments are reluctant to impose such taxes for political reasons, partly influenced by concerns with their distributional effects. There are also concerns about the uncertainties in the estimates of external costs that we have highlighted. Thus emissions charges for fossil fuel plants are rare though there are some examples, where the level of the charges are well below the estimated external costs (Markandya, 2011) ${ }^{12}$.

Most policies that have been introduced fall into two categories. First, is the requirement of standards that reduce the external costs arising from power generation. The decisions to adopt these standards are increasingly subject to a benefit cost analysis for which the benefits are derived from estimates of the reduction in external costs. Such benefits are compared against the additional costs of establishing cleaner fossil fuel plants. The ExternE data presented here, for example, have been used to determine the details of a large number of EU directives for the power sector.

Second policies are introduced to provide subsidies to cleaner sources of electricity, such as renewables. In Europe most subsides take the form of feed-in tariffs (obliging power utilities to buy power generated from renewable sources at a premium) but there are also grants and tax credits for investment in renewable

${ }^{12}$ Since all emission do not have the same damages, a tax based on average damages per unit of emissions is also an approximation to the ideal instrument. So is a permit system where the number of permits are determined based on the point at which average damages unit are equal to the marginal costs of abatement. Considerable work has shown, however, that under a wide range of conditions tax or permit schemes are the most efficient among the practical instruments. The choice between permits and taxes is partly based on political considerations and where what one perceives is the main source of uncertainty to lie (TIETENBERG, 1990; WEIZMANN, 1974). 
sources $^{13}$. It is fair to say that the levels of subsidies have been less influenced by the literature on external cost and more by the expectation that these subsides will help to lower their costs or renewable sources through 'learning by doing'. Indeed a detailed evaluation of the impacts of renewable subsidies in terms of how much they reduced external costs, plus their benefits in terms of lowering private costs through learning by doing has yet to be undertaken.

In general one has to be careful when using subsidies to address external costs through the mechanisms suggested. The costs of raising public funds to pay the subsides have to be taken into account in the benefit cost analysis and they represent a major debit item against any potential benefit in terms of reduced external effects. Often subsides also generate external consequences of their own. The following have been noted in the literature (Barbier and Markandya, 2012):

- Biofuel subsidies that increase nitrate pollution and increase the international price of staple foods, with negative implications for poor households in developing countries.

- FITs for wind are offered irrespective of where the turbines are located. This can favour high wind areas remote from transmission lines, with the result that more lines are constructed increasing environmental pressures.

- Grants for clean coal technologies have increased the demand for coal, including that with a high ash and sulphur content.

- Irish and EU subsidies for peat fired power plants resulted in destruction of peat bogs and questionable $\mathrm{CO} 2$ savings.

To sum up, the work on external costs has played in important part in our understanding of the right mix of fuels for power generation. The external cost data on coal, oil and gas powered generation has influenced standards for these plants and has led to much cleaner plants. There is some movement to introduce emissions charges or tradable permits as a way to internalise the externalities, but there remain significant political challenges. And there are issues still to be addressed, such as nuclear, and the uncertainties are significant. Work is continuing on these and in the meantime the debate on the best way to internalise the externalities continues.

${ }^{13}$ A feed-in tariff (FIT) is a guaranteed price paid to a generator from a renewable source. A renewable portfolio standard (RPS) is a system that obliges utilities or consumers to source a certain percentage of their power from renewable energy sources. The US has relied more on RPS although some states have FITs for small producers. The advantage of an RPS is that it provides flexibility in terms of how firms make investment and trading decisions. Obligations could be met through the trading of certificates that are allocated to operators of renewable energy plants. The disadvantage is that firms are vulnerable to uncertainty in future electricity and certificate prices. In general the evidence shows that FITs have been more effective than RPS in terms of cost, and they provide more incentives for the less proven technologies but both schemes can place a burden on the public budget, which creates welfare costs of its own 


\section{References}

[1] BARBIER,E. B. and MARKANDYA, A. (2012): A New Blueprint for a Green Economy, forthcoming, Oxfordshire: Taylor and Francis.

[2] EXTERNE (2005): «EXTERNE: Externalities of Energy: Methodology 2005 Update», European Commission, Brussels. ISBN 92-79-00423-9.

[3] KUIK, O.; BRANDER, L.; NIKITINA, N.; NAVRUD, S.; MAGNUSSEN, K. and FALL, E. H. (2008): CASES project, WP3, «Report on the Monetary Valuation of Energy Related Impacts on Land Use Chanhes, acidification, eutrophication, Visual Intrustion and Climate Change».

[4] KRUPNICK, A. J.; MARKANDYA, A. and NICKELL, E. (1993): «The External Costs of Nuclear Power: Ex Ante Damages and Lay Risks», American Journal of Agricultural Economics, 75, pp. 1273-1279.

[5] MARKANDYA, A. (2011): «Environmental Taxation: What Have We Learnt in the Last 30 years?», Rivista di Politica Economica, VII-IX, pp. 11-58.

[6] MARKANDYA, A.; BIGANO, A. and PORCHIA, R. (eds.) (2010): «The Social Costs of Electricity: Scenarios and Policy Implications», Edward Elgar Publishing.

[7] OTT, W.; BAUR, M.; ITEN, R. and VETTORI, A. (2005): «Konsquente Umsetzung des Verursacherprinzips», Umwelt-Materialien, Nr. 201, BUWAL, Bern.

[8] PIGOU, A. (1932): The Economics of Welfare, MacMillan, London.

[9] SPADARO, J. V. and RABL, A. (2008): «Estimating the Uncertainty of Damages Costs of Pollution: A Simple Transparent Method and Typical Results», Environmental Impact Assessment Review, 28, pp. 166-183.

[10] RABL, A. y SPADARO, J. V. (1999): «Estimating damages and costs: An analysis of uncertainties», Environment International, 25 (1), pp. 29-46.

[11] TIETENBERG, T. H. (1990): «Economic Instruments for Environmental Regulation», Oxford Review of Economic Policy, 6 (1), pp. 17-33.

[12] WEITZMAN, M. L. (1974): «Prices Vs. Quantities», Review of Economic Studies, 41. 